\title{
O USO DE TÉCNICAS COMPENSATÓRIAS DE DRENAGEM PARA CONTROLE DOS IMPACTOS DA URBANIZAÇÃO
}

\author{
Use of compensatory techniques on drainage for urban impacts control \\ El uso de las tecnicas compensatorias de drenaje para el control del impacto de la \\ urbanización.
}

\author{
Luciana Márcia Gonçalves \\ Professora Doutora, UFSCar, Brasil \\ lucianamg@ufscar.br \\ Luana F.da Silva Baptista \\ mestre em Engenharia Urbana UFSCAR \\ baptista.luana@yahoo.com.br \\ Rochele Amorim Ribeiro \\ Professora Doutora, UFSCar, Brasil \\ rochele@ufscar.br
}




\section{RESUMO}

A crescente urbanização, gerada pelas novas demandas de oportunidades e de consumo, resultou no excesso de impermeabilização do solo e na alteração do ciclo hidrológico. Como forma de conter estes impactos negativos e estimular o planejamento urbano que possibilite o escoamento adequado das águas urbanas, propõe-se a implantação de técnicas compensatórias. Com o intuito de verificar sua funcionalidade, analisou-se a inserção de dispositivos através da desconexão da rede publica pluvial em uma microbacia de estudo em um campus universitário. Foram comparados os aspectos urbanísticos, hidrológicos, ambientais e sanitários, e seus respectivos parâmetros em dois cenários de desenvolvimento. Os resultados comparados com a urbanização convencional demonstraram uma diminuição de $42,94 \%$ do volume de escoamento superficial e de $41,93 \%$ da vazão de pico.

PALAVRAS-CHAVE: técnicas compensatórias, urbanização de baixo Impacto, planejamento urbano sustentável

\section{ABSTRACT}

The growing urbanization, generated by new demands and opportunities of consumption, resulted in excessive soil sealing and impacts on hydrological cycle. This study proposes the compensatory techniques in order to avoid negative impacts of urbanization and to encourage the urban planning to improve a suitable urban water drainage. Traditional infrastructure drainage was disable by means of the disconnection of water pipes and replaced for compensatory techniques devices. These techniques were built in a watershed in a university campus and were evaluated by this research. The urban, hydrological and environmental aspects, and their parameters, were evaluated in two development scenarios. The results, when compared with traditional urban drainage, show a decrease of $42.94 \%$ of runoff volume and $42.94 \%$ of the peak flow.

KEYWORDS: compensatory techniques; low impact development; sustainable urban planning.

\section{RESUMEN}

La creciente urbanización, generada por las nuevas exigencias del consumo y oportunidades resulta in el exceso de estanqueidad del suelo y en los cambios en el ciclo del agua. Con el fin de detener los impactos negativos y también estimular la planificación urbana adecuada para la condición del flujo de aguas pluviales, se propone la implementación de técnicas compensatorias. Con el fin de comprobar su funcionalidad, analizado los dispositivos de inserción a través de la desconexión de la red pública de lluvia en el estudio de las cuencas hidrográficas en el campus de la universidad. Fueron comparados los aspectos urbanos, hidrológicos, ambientales y sanitarios, y sus parámetros en dos escenarios de desarrollo. Los resultados se compararon con los de la urbanización convencional y demostraron una disminución $42,94 \%$ del volumen de la escorrentía y $41,93 \%$ de flujo máximo.

PALABRAS CLAVE: técnicas compensatorias, bajo impacto de la urbanización, la planificación urbana sostenible 


\section{INTRODUÇÃO}

Os processos históricos sociais e econômicos pelos quais as cidades se constroem, caminham paralelamente às transformações espaciais identificadas ao longo do tempo. Neste contexto, 0 Brasil se caracteriza por passar por um processo de urbanização muito intenso há aproximadamente 60 anos. Em 1960 cerca de 30\% da população vivia nas cidades, em 2010 constatou-se que $84,4 \%$ moravam em áreas urbanas (IBGE, 2010).

Essa migração trouxe para o país consequências estruturais e sociais: com o aumento da renda per capita, novos padrões de consumo foram sendo definidos, estabelecendo novas demandas de infraestrutura. Por outro lado, dentro das redes de infraestrutura existentes, a rede de drenagem deve ser considerada de uma forma diferente das demais redes urbanas, uma vez que não precisa necessariamente de um sistema construído para seu funcionamento, pois a tendência natural é o escoamento e infiltração das águas, desde que seus caminhos não sejam obstruídos (Baptista et. al., 2011).

O baixo impacto da urbanização no processo de desenvolvimento das cidades depende de vários aspectos que compõem um quadro complexo, integrado e multidisciplinar. Através do planejamento urbano deve-se considerar a gestão das infraestruturas, nas quais se destaca neste trabalho a drenagem urbana sustentável, importante componente do sistema de infraestrutura urbana que pode influenciar consideravelmente no uso e ocupação do solo urbano, além de exigir a análise dos parâmetros estruturais de projeto e de gestão de suas técnicas.

Com o aumento da ocupação das terras urbanizadas, que resultaram em ampliação de áreas impermeabilizadas, o destino das águas pluviais sofreu significativas alterações, causando mudanças no ciclo hidrológico natural. Como forma de conter este impacto, tem-se aplicado nas cidades o manejo sustentável das águas da chuva. Seu princípio é reduzir os danos promovidos pela impermeabilização do solo, diminuir a velocidade de escoamento superficial, diminuir as vazões de pico e a reduzir o tempo de concentração. Assim, o planejamento urbano aliado a técnicas sustentáveis de drenagem urbana devem estimular a permanência de áreas com cobertura vegetal e/ou a compensação das áreas construídas a fim de possibilitar o escoamento natural das águas.

Segundo Tucci (1995), o aumento do escoamento superficial pluvial gera impactos nocivos por meio de inundações de áreas ribeirinhas e pelos alagamentos decorrentes da urbanização e/ou da obstrução do escoamento, já que grande parte da vazão pluvial é canalizada. No processo tradicional de urbanização, as áreas de cobertura vegetal são substituídas por materiais impermeáveis, reduzindo a infiltração do solo . Ademais, essas alterações interagem de acordo com as áreas onde há maior ou menor precipitação de chuvas e onde os sistemas de drenagem são aplicados, já que no instante de sua construção, não atendem mais as demandas para as quais foram estruturados, devido aos processos acelerados de impermeabilização das cidades. (Santos, 2006). Para conter tal situação, encontram-se, em uso crescente, as técnicas de drenagem compensatórias (ou alternativas) para a drenagem urbana (TC).

Diferentemente da drenagem urbana clássica, onde a gestão das águas visa apenas às situações de cheia, o que demanda elevados custos com canalização e alterações no curso natural dos rios, a drenagem compensatória destina-se à diminuição dos impactos da 
urbanização através do aumento das taxas de infiltração da água da chuva no solo e da desaceleração do escoamento superficial das águas, resgatando o hidrograma das condições de pré-urbanização (Tucci, 1995).

As Técnicas Compensatórias (TCs) ou as Best Management Practices (BMPs) foram desenvolvidas nos anos 70, na América do Norte, e se aplicam em locais onde há disponibilidade de território e áreas verdes, preferencialmente. Conforme Baptista et. al. (2011), os dez primeiros minutos de chuva carregam uma elevada carga de poluição, já que as águas pluviais "lavam" a cidade. Desta forma foram desenvolvidas técnicas compensatórias que visam controlar a quantidade de água escoada superficialmente para as galerias e rios, seja pela infiltração ou detenção, seja pela diminuição da velocidade de escoamento e do aumento da taxa de evapotranspiração, possibilitando a proteção da qualidade da água e a implantação de paisagens ambientalmente agradáveis. Estas técnicas também são consideradas alternativas por considerarem os impactos da urbanização de forma global, tomando a bacia hidrográfica como base de estudo, e buscando compensar, sistematicamente, os efeitos da urbanização. Esta compensação é efetuada através do controle na fonte (em lotes) da produção de excedente de água com o intuito de evitar sua transferência rápida para as áreas à jusante (Baptista et. al., 2011). Ademais, as técnicas possuem um caráter multifuncional, já que permite ganhos urbanos e paisagísticos, pois podem estar associadas a áreas de lazer.

Neste trabalho, as TCs foram analisadas sob o ponto de vista da funcionalidade e da integração, e foram comparadas a dois cenários de estudo referencial prático, localizados na microbacia do campus da Universidade Federal de São Carlos (UFSCar), na cidade de São Carlos (SP). No campus, tal qual nos processos de urbanização clássicos, passa-se por um processo de expansão física e, consequentemente, apresenta uma ampliação das áreas impermeabilizadas advindas das novas necessidades de edificações, vias e estacionamentos. A partir da comparação entre duas situações de desenvolvimento e seus respectivos aspectos ambientais, sanitários, hidrológicos e urbanísticos, foi possível verificar e identificar como as técnicas compensatórias influenciam nos parâmetros e consequentemente no resultado da paisagem hidrologicamente funcional. Para isso, tais situações foram demonstradas por cenários de ocupação representados por mapas, tabelas, gráficos e figuras. Esta microcrobacia de estudo está localizada na região norte do campus e possui uma área total de 4,65 ha. A Figura 1 ilustra a localização da microbacia.

Como método de analise, avaliaram-se os aspectos ambientais , hidrológicos e urbanísticos da microbacia em dois diferentes cenários de desenvolvimento: 1. Cenário convencional (contempla totalmente a necessidade de rede pública de drenagem) e 2. Cenário com instalação de TCs ( desconexão de áreas impermeabilizadas da rede ) . 
Figura 1: Localização da microbacia na Área Norte da UFSCar

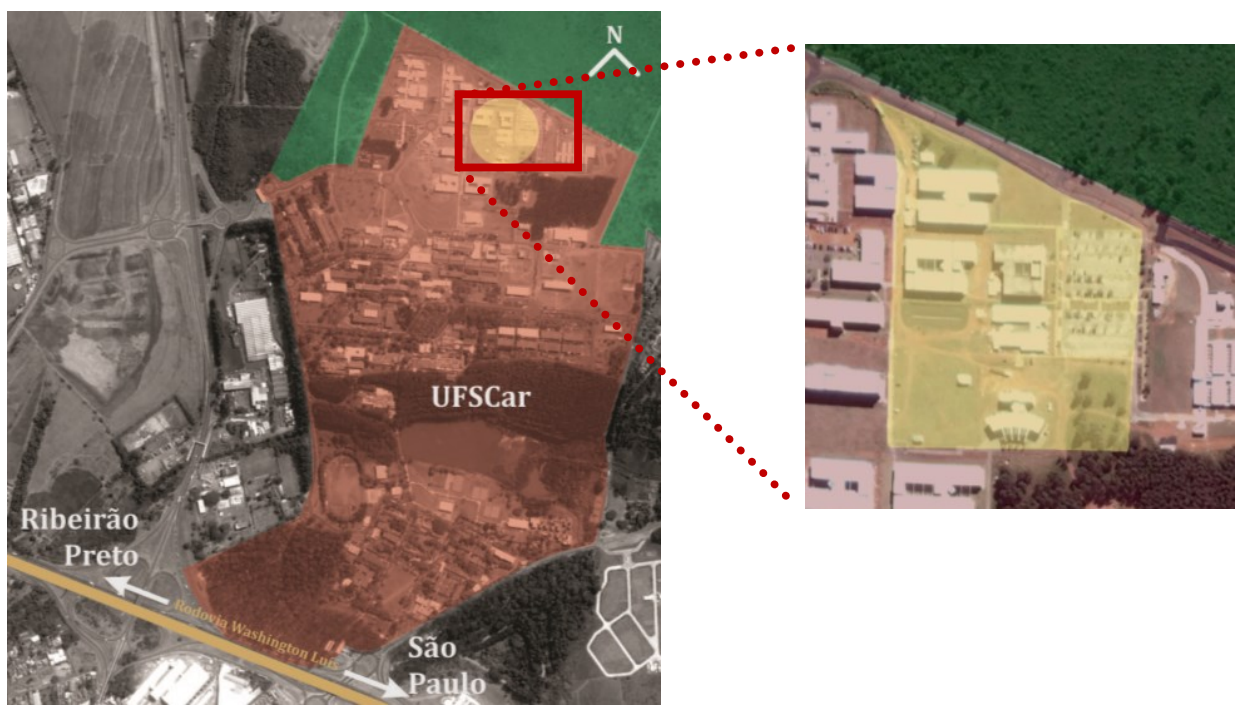

Fonte: Autoria Própria

Os aspectos ambientais se caracterizam por serem elementos que interagem com o meio ambiente, sejam eles naturais ou humanos. Nestes aspectos, são incluídas as preocupações sanitárias que se configuram por questões que abrangem a saúde pública. Integrando aspectos ambientais e hidrológicos, os parâmetros de projeto garantem a permanência mais adequada das condições naturais do ciclo hidrológico, seja pela configuração estabelecida na paisagem urbana, seja pela sua qualidade.

Os aspectos hidrológicos visam o resgate das condições hidrológicas de pré-urbanização. Para isso, são utilizados parâmetros como Volume (V), Vazão de Pico (Q), Tempo de Concentração (Tc), Intensidade (I) e controle da qualidade da água. Com o levantamento desses parâmetros foi possível realizar as devidas comparações hidrológicas entre os cenários propostos.

Para os cálculos, foi adotado o Método Racional, pela sua simplicidade e por ser indicado para situações em que a bacia possui área inferior a $2,5 \mathrm{~km}^{2}$ ( VIESSMAN et. al., 1989).

Os aspectos urbanísticos foram representados por parâmetros que caracterizam a bacia através do seu uso, da infraestrutura existente e da relação entre áreas livres e as áreas ocupadas. Uma vez definidos os aspectos e parâmetros, foi estruturada uma tabela baseada nos critérios criados por Tavanti (2009), com o intuito de facilitar a legibilidade de cada cenário. Os quadros 2 e 3 foram preenchidos a partir destes critérios.

\section{CENARIO 1.}

O primeiro cenário a ser descrito e caracterizado para fins deste estudo foi o que se denominou: Urbanização Convencional - Cenário 1. Neste contexto de urbanização procura-se escoar toda a água da chuva no menor tempo possível. E para isso, utilizam-se tubulações que encaminham essas águas para as áreas a jusante, ou seja, de menor cota.

Para a quantificação deste cenário, foi utilizado o mapeamento disponibilizado pelo Escritório e Desenvolvimento Físico da Universidade - EDF Maio/2013) através do software AutoCAD, ou 
seja por meio da planta digitalizada, sendo possível definir os limites territoriais e quantificar espacialmente as áreas a serem analisadas. O cenário convencional está ilustrado na Figura 2.

Figura 2. Microbacia com cenário convencional conectado à rede de drenagem do campus

(Sistema de drenagem convencional da microbacia em destaque)

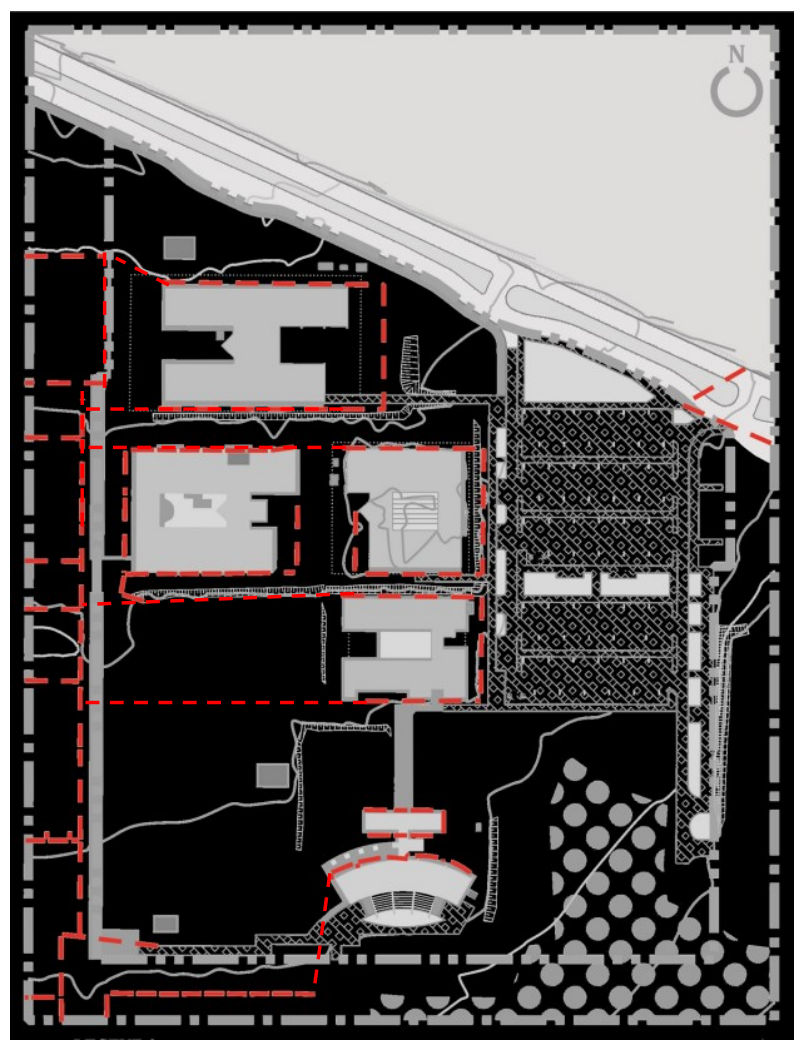

- - - - Linhas da Rede Pluvial

Fonte: Autoria Própria

Para se entender a dinâmica entre o entorno e a microbacia, bem como suas diversas interferências foram realizadas visitas in loco e ensaios práticos de acordo com as normas específicas. Os ensaios feitos visaram conhecer o índice de permeabilidade e infiltração do solo na microbacia e confirmaram a intensa compactação do solo na área à jusante da microbacia, justificando o surgimento de alagamentos em seu entorno no instante de uma chuva.

\section{CENÁRIO 2}

O cenário 2, Urbanização convencional com uso de TCs, caracteriza-se por receber, sobre o mesmo contexto de urbanização do cenário 1, as Técnicas Compensatórias construídas pelo grupo de pesquisa G-Hidro (2016) na microbacia de estudo. Neste cenário foram implantadas as TCs com o intuito de reduzir a necessidade de implantação dos dispositivos tradicionais de microdrenagem como boca de lobo e sarjetas, favorecer a infiltração e diminuir os impactos hidrológicos. 
Para atingir tais objetivos, parte-se da compreensão do planejamento e da gestão praticados na microbacia com o intuito de determinar as possibilidades de construção das técnicas compensatórias, considerando que estas devem possuir dimensão mais reduzida devido à complexidade da sua construção em espaços já ocupados por edificações. A relação entre a taxa de ocupação do solo e sua influência na composição das áreas impermeáveis também permite análises quanto ao desenvolvimento das TCs.

Trata-se, portanto, de uma abordagem comparativa, na qual a inserção de TCs, será avaliada do ponto de vista hidrológico, ambiental e paisagístico. Para a avaliação do cenário 2 foram utilizadas estratégias que consideram a mitigação dos impactos já ocorridos pela urbanização, por meio da redução do Coeficiente de Escoamento (C) e da diminuição da Vazão de Pico (Q). Através da implantação de valas vegetadas, aumento dos caminhos e dos fluxos das águas, bem como o estímulo ao acréscimo das áreas de cobertura vegetal, pôde ser verificado a relação existente entre o escoamento da águas da chuva e o desempenho de áreas com vegetação.

Por meio do mapeamento, das visitas in loco e da identificação dos controles hidrológicos a serem atendidos, como volume a ser armazenado e espaços a serem desconectados, foi possível estabelecer e indicar quais estruturas melhor compensam os conflitos identificados. Dessa forma, se quantificou os parâmetros e estabeleceram-se as comparações necessárias quanto aos ganhos e impactos negativos da paisagem. O cenário 2 está ilustrado na Figura 3.

\section{CRITÉRIO DE ESCOLHAS DE TIPO E DIMENSIONAMENTO DAS TCS}

$\mathrm{Na}$ microbacia foram adotadas diferentes tipos de técnicas compensatórias, escolhidas conforme os seguintes critérios:

- Critérios físicos: a topografia local apresenta uma declividade satisfatória para algumas técnicas, por não pretender deixar um aporte permanente de água, por não optar pela existência de um exutório permanente e pelo nível do lençol freático ser profundo;

- Critérios urbanísticos e de infraestrutura: disponibilidade de espaço e ausência de uma interferência direta das redes existentes no local;

Critérios sanitários e ambientais: pelo fato de água ser somente proveniente de telhados, não ocorrendo risco de poluição do solo; e ausência de estagnação da água no local.

Diante das análises das condições locais e volumes de água a serem infiltrados ou conduzidos, foram definidas as seguintes técnicas: Sistema integrado de Filtro-Vala-Trincheira (FVT), Plano de Infiltração ( PI) e Poço de Infiltração (PO). Cada local de implantação da TC foi decidido conforme a necessidade de armazenamento do prédio ou da área impermeabilizada a ser compensada, bem como a área livre disponível na proximidade. 


\section{da Alta Paculista}

Figura 3: Localização das TCs no cenário 2.

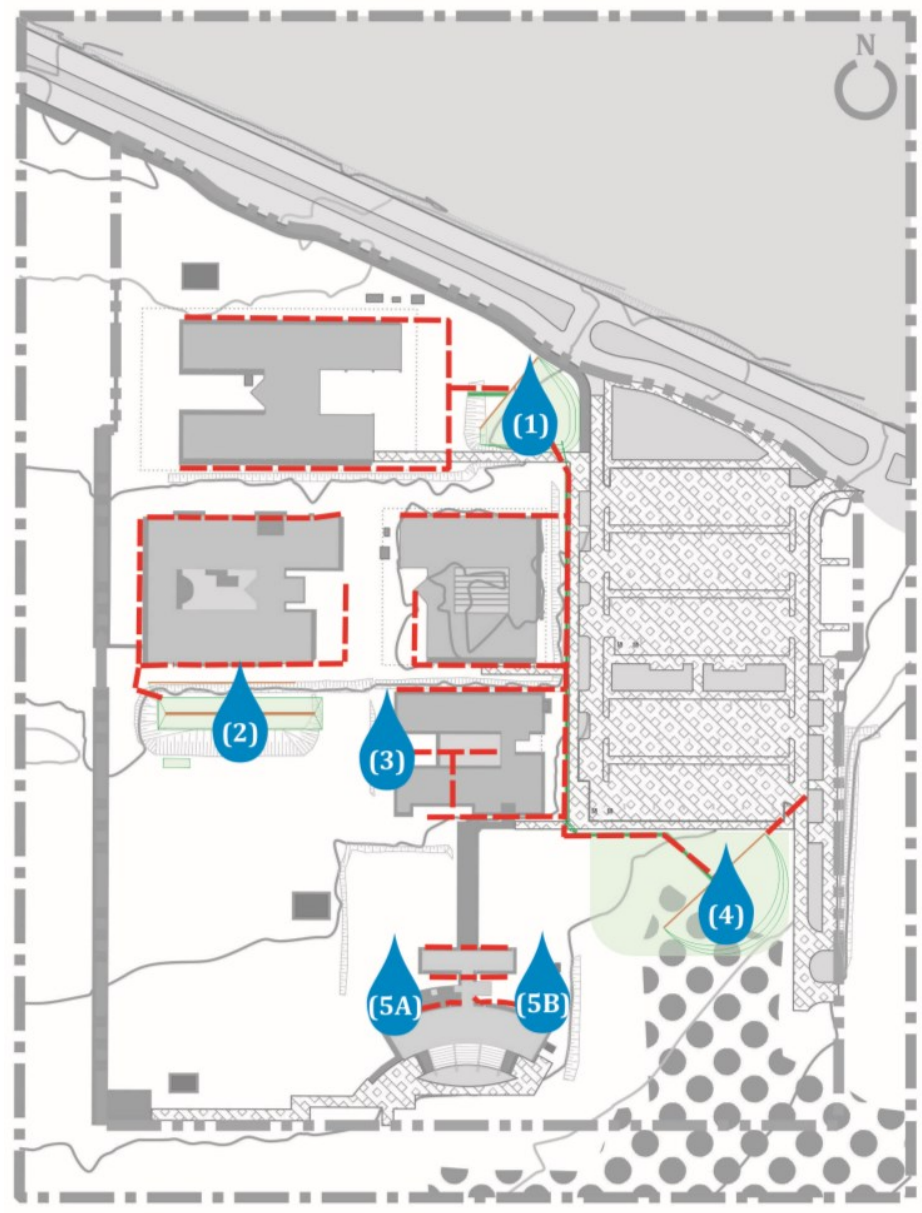

(1) Plano de Infiltração - Prédio da Fisioterapia

(2) Sistema Filtro - Vala - Trincheira - Prédio da Medicina

(3) Poço de Infiltração - Prédio da Gerontologia

(4) Plano de Infiltração - Estacionamento

(5A) Poço de Infiltração - Prédio do Núcleo de Formação dos Professores

(5B) Poço de Infiltração - Prédio do Núcleo de Formação dos Professores

Fonte: Autoria própria

As TCs no cenario 2 encontram-se quase todas implantadas por meio de financiamentos de pesquisas, sendo objeto de investigações científicas. Destacam-se nos estudos as seguintes TCs e seus autores : o Sistema Filtro - Vala - Trincheira (item 2 da Figura 2) foi estudado por GUTIERREZ (2011) e LUCAS (2011); o Poço de Infiltração do Núcleo de Formação dos Professores (item 5B da Figura 2) foi dimensionado e estudado por ANGELINI SOBRINHA (2012); os planos de Infiltração (itens 1 e 4 da Figura 2) foram estudados por TECEDOR( 2015) e SILVA (2015). Já a TC 5A (Figura 2) ainda não foi construída.

\section{PLANO DE INFILTRAÇÃO}

O Plano de Infiltração é uma TC pode ser definida como uma área rebaixada, com profundidade reduzida, coberta com grama inclusive nas laterais, e que recebe água pluvial 
vindas de superfícies impermeáveis (MOURA, 2005). Esse tipo de dispositivo deve ser utilizado em terrenos com baixa declividade, visto que em terrenos acidentados a água ganha velocidade e permanece pouco tempo em contato com o solo, não permitindo sua adequada infiltração (HOLZ e TASSI, 2007).O funcionamento do Plano de Infiltração da microbacia UFSCAR ocorre conforme ilustrado na Figura 4.

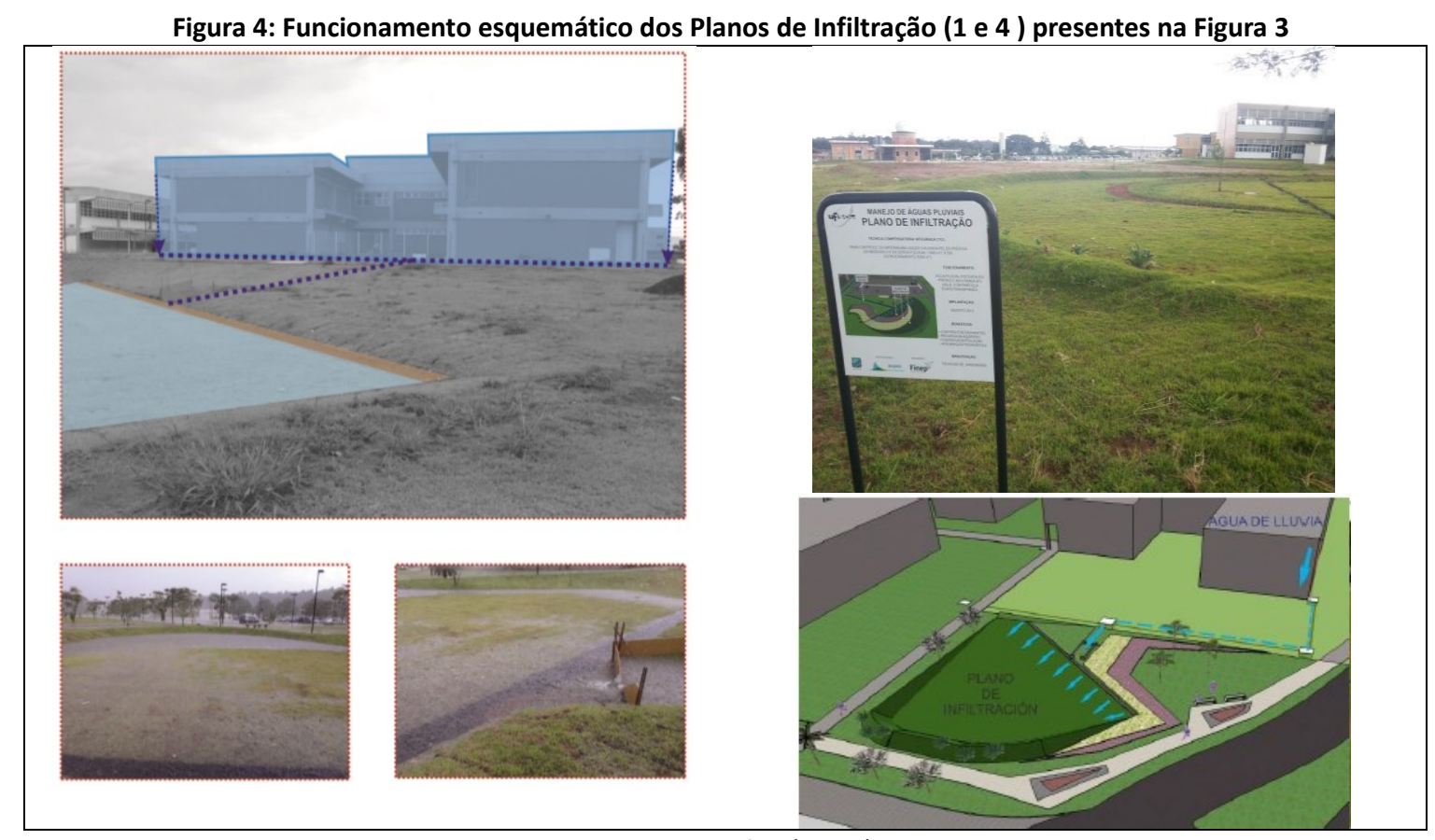

Fonte: G-Hidro (2016)

Após o escoamento para o Plano de Infiltração, as águas pluviais ficam armazenadas temporariamente, já que a água pode ser infiltrada no solo ou escoar através de um dispositivo instalado no final da estrutura. O Plano de Infiltração foi projetado com uma forma de arco de elipse, sendo a dimensão do semieixo maior de $25,85 \mathrm{~m}$ e do semieixo menor de $19,90 \mathrm{~m}$, com um volume total de armazenamento de $111,34 \mathrm{~m}^{3}$.

\section{Poço de Infiltração}

Os Poços de Infiltração são TCs pontuais, de controle na fonte e caracterizam-se por necessitar de pequenas áreas para sua implantação. Tem função de minimizar as vazões de pico e aumentar a quantidade de água que infiltra no solo, contribuindo para a diminuição do volume do escoamento superficial (ANGELINI SOBRINHA, 2012). Já o esvaziamento da água neste dispositivo pode ser por infiltração no solo ou pelo lençol freático. Em locais onde a camada superficial é pouco permeável e as camadas mais profundas permeáveis, este dispositivo se mostra como uma solução bastante adequada (BAPTISTA et. al., 2011).

\section{Filtro - Vala - Trincheira}

O Sistema Filtro - Vala - Trincheira (FVT) foi a primeira TC construída na microbacia. Segundo Baptista et. al. (2011), as trincheiras são técnicas lineares implementadas junto à superfície, 
com pequena largura e profundidade, porém com dimensões longitudinais mais significativas. Podem ser usadas em canteiros centrais e calçadas, ao longo do sistema viário, em jardins, áreas verdes ou terrenos esportivos. O funcionamento do Sistema FVT ocorre de acordo com a Figura 5 e no caso de um extravasamento, as águas são encaminhadas para a rede convencional existente (LUCAS, 2011).

Figura 5: Funcionamento esquemático do Sistema FVT.

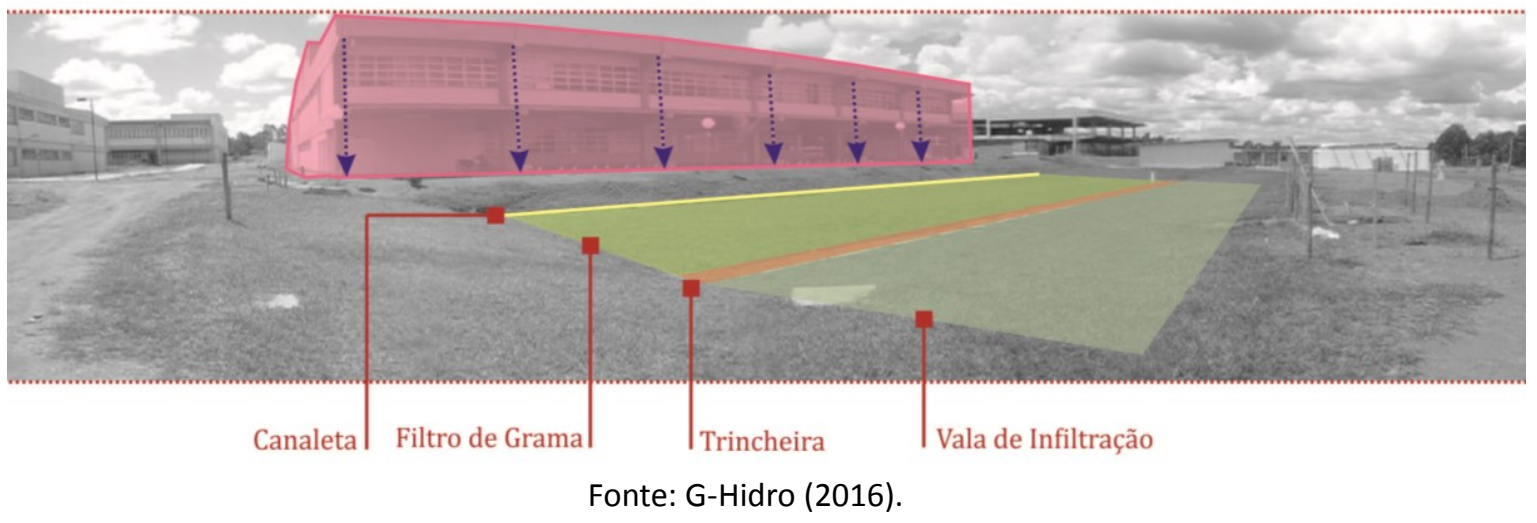

\section{RESULTADOS}

A partir da análise das TCs, seja por avaliação in loco, seja por meio de modelos de simulação, foram realizadas as analises conforme critérios previamente estabelecidos. A comparação entre cada cenário teve como principal resultado o Hidrograma de Vazão de Pico $(Q) \times$ Tempo de Concentração $(\mathrm{Tc})$, cujos resultados podem ser visualizados no Gráfico 1. Em relação ao Cenário 2, há evidências de que sua inserção no espaço urbanizado pode reduz os impactos, pois há uma diminuição no valor da vazão de pico, apresentando uma redução de $41,93 \%$ da vazão de pico em relação ao Cenário 1.( Quadro 1)

Gráfico 1: Hidrogramas de Vazão de Pico X Tempo de Concentração.

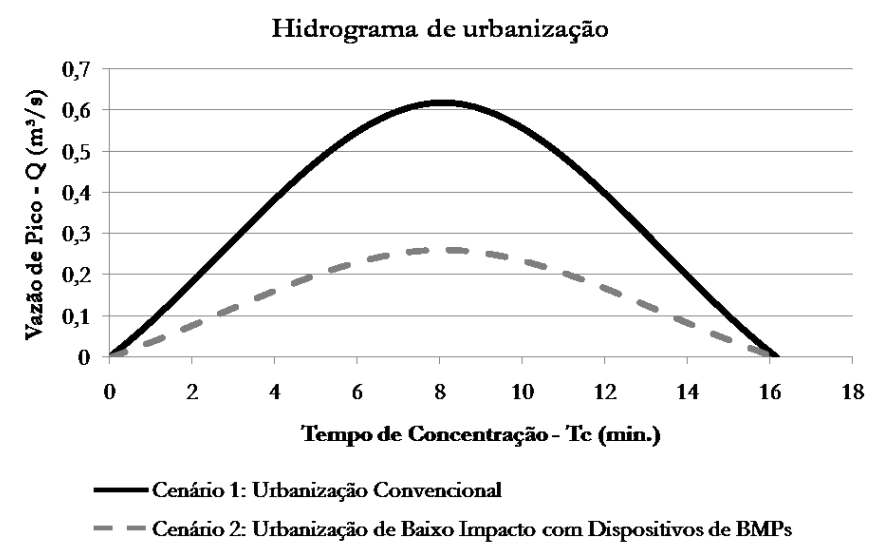

Fonte: Autoria Própria

No Quadro 1 são demostrados os valores extraídos das pesquisas individuais e comparados neste trabalho para fins de análise do resultado na microbacia como um todo. $O$ uso dos dispositivos compensatórios possibilita a questão multifuncional da área ocupada. As áreas 
verdes nos Cenários 1 e 2 correspondem a 67,47\% da área da microbacia. Já a implantação das técnicas permitiu que houvesse uma redução nas Áreas Impermeáveis Diretamente Conectadas (AIDC), o que possibilitou uma diminuição do volume das águas pluviais que chegam as tubulações. Também é importante ressaltar que a implantação das técnicas não necessitou de grandes movimentações de terra, garantindo melhorias na relação com os parâmetros hidrológicos.

Outra consideração é quanto ao VESD. Com a aplicação parcial das estruturas compensatórias, seu volume cai $42,94 \%$. No Cenário 2 , o volume de água armazenado nas TCs devido à desconexão parcial da rede foi de $570,65 \mathrm{~m}^{3}$.

Quadro 1: Comparação entre os cenários quanto aos Aspectos Hidrológicos.

\begin{tabular}{|c|c|c|}
\hline \multicolumn{3}{|c|}{ ASPECTOSHIDROLÓGICOS } \\
\hline PARÂMETROS & CENÁRIO 1 & CENÁRIO 2 \\
\hline Caracterīzaçāo do Sistema de Drenagem & $\begin{array}{r}\text { Escoamentopor condutos } \\
\text { enterrados }\end{array}$ & $\begin{array}{r}\text { Escoamentopor canais } \\
\text { gramados e condutos } \\
\text { entenrados }\end{array}$ \\
\hline Coeficiente de Escoamento Superficial Ponderado-C & 0,35 & 0,15 \\
\hline Intensidade (mm/h) & 135,31 & 135,31 \\
\hline Tempo de Concentraçāo-Tc (min) & 8,09 & 8,09 \\
\hline Tempo de Retomo-Tr (anos) & 10 & 10 \\
\hline Vazāo de Pico- $Q\left(\mathrm{~m}^{2} / \mathrm{s}\right)$ & 0,62 & 0,26 \\
\hline Volume de Armazenamento para a Área $-V_{\Delta}\left(m^{2}\right)$ & 283,54 & 55,31 \\
\hline $\begin{array}{l}\text { Volume de Armazenamento para Desconexāode Áreas } \\
\text { Impermé́veis Diretamente Conectadas- } V_{\text {AIDc }}\left(\mathbf{m}^{z}\right)\end{array}$ & $\mathbf{0}$ & 570,65 \\
\hline Volume de Escoamento SuperficialDireto-V $V_{\mathrm{ESD}}\left(\mathrm{m}^{2}\right)$ & 299,62 & 128,66 \\
\hline
\end{tabular}

Fonte: Autoria Própria

Aspectos Ambientais e Sanitários

O Risco de Água com Finos e com Poluição, além da Poluição Subterrânea, é um dos impactos mais presentes na urbanização convencional. No entanto, com a implantação das TCs foi possível reduzi-los. No Cenário 2, tais riscos são ausentes devido a implantação das estruturas compensatórias. Assim, há um impedimento de que esse material chegue ao nível subterrâneo, pois na urbanização convencional a tubulação encaminha toda água que possui carga poluidora para o corpo receptor final. Já o risco sanitário está ausente em todos os cenários, devido: ao Cenário 1 possuir o sistema de drenagem convencional dimensionado para escoar toda água o mais rápido possível; e ao Cenários 2 devido ao fato de ter o dimensionamento das técnicas considerando a permanência da água superfície por no máximo 24 horas, sendo que esta situação somente ocorre em grandes eventos, quando o solo já se encontra saturado. Este dados podem ser verificados no Quadro 2. 
Quadro 2 - Comparação entre os cenários quanto aos Aspectos Ambientais e Sanitários.

\begin{tabular}{|c|c|c|c|}
\hline \multicolumn{4}{|c|}{ ASPECTOS AMBIENTAIS E SANITÁRIOS } \\
\hline \multicolumn{2}{|c|}{ PARÂMETROS } & CENÁRIO I & CENÁRIO 2 \\
\hline \multicolumn{2}{|l|}{ Microbacia (ha) } & 4,65 & 4,65 \\
\hline \multirow{3}{*}{ Áreas Verdes (m²) } & Áreas de Gramados ( $\left.\mathbf{m}^{2}\right)$ & $26.484,06$ & $26.484,06$ \\
\hline & Arborizaçäo (unidade) & 193 & 193 \\
\hline & Eucaliptal $\left(\mathbf{m}^{2}\right)$ & $2.479,21$ & $2.479,21$ \\
\hline \multicolumn{2}{|c|}{ Condutividade Hidráaulica Saturada do Solo (Ksat) } & $\begin{array}{l}\text { Para } 30 \mathrm{cm:} 5,0 \times 10-5 \mathrm{~m} / \mathrm{s} \\
\text { Para } 50 \mathrm{cm:} 5,8 \times 10-5 \mathrm{~m} / \mathrm{s}\end{array}$ & $\begin{array}{l}\text { Para } 30 \mathrm{~cm}: 5,0 \times 10-5 \mathrm{~m} / \mathrm{s} \\
\text { Para } 50 \mathrm{~cm}: 5,8 \times 10-5 \mathrm{~m} / \mathrm{s}\end{array}$ \\
\hline \multicolumn{2}{|l|}{ Compactaçäo } & $\begin{array}{r}\text { Variou entre } 92,5 \mathrm{na} \\
\text { superficie e 72,3 na } \\
\text { profundidadede } 90 \mathrm{~cm} \\
\end{array}$ & $\begin{array}{r}\text { Variou entre } 92,5 \mathrm{na} \\
\text { superficie e } 72,3 \mathrm{na} \\
\text { profundidadede } 90 \mathrm{~cm}\end{array}$ \\
\hline \multicolumn{2}{|c|}{ Risco de Água com Finos e Poluição } & Existente & Ausente \\
\hline \multicolumn{2}{|c|}{ Risco de Poluição Subterrânea } & Existente & Ausente \\
\hline \multicolumn{2}{|l|}{ Risco Sanitário } & Ausente & Ausente \\
\hline
\end{tabular}

Fonte: Autoria Própria

Aspectos Urbanísticos

A paisagem multifuncional foi obtida nos projetos desenvolvidos a fim de revelar a possibilidade de integração das técnicas com o espaço do entorno, inclusive com seus usos. No projeto para o poço de infiltração com superfície rebaixada foi possível promover a integração entre a edificação o e o Poço de Infiltração promovendo usos múltiplos, como infiltração e lazer em uma só estrutura. As características urbanísticas do poço de infiltração pode ser visualizadas na Figura 6.

Figura 6- Poço de infiltração com superfície rebaixada.

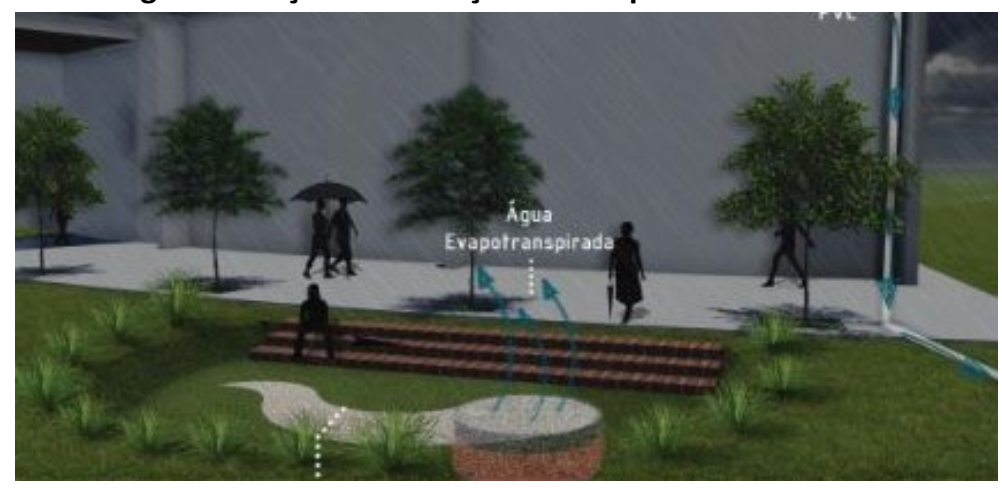

Fonte: G-Hidro,2016

\section{CONSIDERAÇÕES FINAIS}

Por fim a comparação para fins de analise da eficiência do cenário 2 da microbacia de estudo, foi realizada a partir da analise dos aspectos ambientais, hidrológicos e urbanísticos considerando as alterações provocadas com a implantação das TCs no Cenário 2. As TCs foram executadas nas áreas livres da microbacia de acordo com os dimensionamentos calculados 
para proceder a desconexão da rede. Os resultados da avaliação dos cenários podem ser resumidos nos seguintes comentários:

(1) Quanto aos aspectos ambientais da urbanização convenciona I- cenário 1, identificou-se que as áreas verdes correspondem a $67,47 \%$ dos 4,65 ha totais. Constata-se a existência de risco de água com finos e poluição ou risco sanitário, já que existe uma urbanização e automóveis circulando no local. Conforme encontrado nos ensaios de duplo anel (permeabilidade do solo), realizados pelo G-Hidro (2016), o solo apresentou um Ksat que

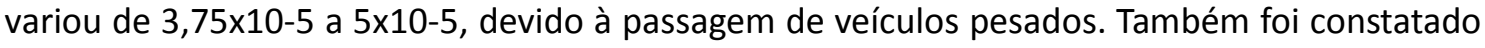
in loco que a área do estacionamento é um ponto de alagamento, já que escoa a água das vias do seu entorno.

(2) Quanto aos aspectos hidrológicos do cenário 1, que por sua vez já apresentam alterações, se comparados a um cenário de pré urbanização, este apresenta-se totalmente canalizado.. Considerando o fato de que a microbacia possui o sistema de drenagem canalizado, foi encontrado um Tc de $8,09 \mathrm{~min}$ para uma I $=135,31 \mathrm{~mm} / \mathrm{h}$ e uma $Q=0,62 \mathrm{~m} / \mathrm{s}$. Por seguinte, 0 VESD foi de $299,62 \mathrm{~m}^{3}$, e o VA $=283,54 \mathrm{~m}^{3}$.

(3) Quanto aos aspectos urbanísticos do cenário 1 pôde verificar, através das plantas do campus e da constatação in loco, que havia grandes áreas impermeabilizadas, inclusive com previsão de expansão das edificações e acréscimo de áreas de calçamento para pedestres. Apesar da área dos edifícios possuir uma Taxa de Ocupação (TO) de 13,56\%, suas calçadas (com largura variando de 1,20 m a 6,00 m), vias e estacionamento ocupam um grande espaço da microbacia, o que causa alterações no volume e percurso de escoamento natural das águas. (4) Quanto aos aspectos ambientais e sanitários do cenário alternativo com uso das TCs afirmase que não há risco sanitário uma vez que às técnicas compensatórias foram dimensionadas para que a água permaneça na estrutura por no máximo 24 horas. As próprias estruturas fazem uma filtragem do material particulado, diminuindo assim a carga poluidora das águas que infiltram.

(5) Quanto aos aspectos hidrológicos do cenário com Técnicas Compensatórias, verificou-se a eficácia das estruturas implantadas, assim como a sua contribuição para a paisagem e para o sistema de drenagem. As estruturas implantadas foram dimensionadas para escoar as áreas dos telhados próximos a sua localização ou para conduzir através dos canais gramados as águas de calçamentos e estacionamento da microbacia. Visando minimizar os efeitos da urbanização na microbacia, foram dimensionados dispositivos que buscam a retenção e a infiltração das águas precipitadas, fazendo com que as vazões sejam rearranjadas temporalmente e que haja uma diminuição do volume escoado, permitindo a redução de alagamentos e obtendo ganhos na qualidade das águas pluviais. Numa análise global da microbacia, foi identificado um Coeficiente de Escoamento (C) de 0,15 com um Tc $=8,09$ minutos, para uma intensidade de $135,31 \mathrm{~mm} / \mathrm{h}$ e um $\operatorname{Tr}$ de 10 anos. Consequentemente, sua Vazão de Pico foi para $0,26 \mathrm{~m}^{3} / \mathrm{s}$, com um VA $=55,31 \mathrm{~m}^{3}$, um VESD $=128,66 \mathrm{~m}^{3}$ e um VAIDC $=$ $570,65 \mathrm{~m}^{3}$, sendo este último correspondente ao somatório do volume de todas as técnicas compensatórias. 
(6) Por fim, pode-se afirmar que além do evidenciado ganho ambiental e hidrológico, os ganhos agregadores aos aspectos urbanísticos do cenário 2 comprovam que as TCs corroboram com a projeto sustentável do campus.

A presença humana sempre trará modificações à paisagem e consequentes impactos, Por isso, a importância da busca pelo menor impacto no processo de urbanização. Do ponto de vista hidrológico, manter as condições pré-urbanização, ou minimizar os impactos com dispositivos compensatórios contribui para a sustentabilidade urbano-ambiental.

Todos os resultados encontrados na microbacia possuem relação com o tipo de urbanização identificada no local e com seu nível de adensamento e uso do espaço. A microbacia de estudo apresenta densidade média abaixo dos valores de áreas adensadas urbanas e possui grandes áreas verdes livres porém como modelo, comporta-se como um fragmento de cidade na qual as edificações, pisos e vias impermeabilizam e conduzem ao cenário de enchentes e inundações conhecidas. Também é válido ressaltar que em todos os aspectos verificados houve uma melhora nos dados hidrológicos identificados no Cenário 2, devido à presença das TCs, em especial quanto ao volume escoado e a vazão de pico, que diminuíram consideravelmente.

\section{REFERÊNCIAS BIBLIOGRÁFICAS}

ANGELINI SOBRINHA, L. Monitoramento e modelagem de um poço de Infiltração de águas pluviais em escala real e com filtro na tampa. 2012. 149 p. Dissertação (Mestrado em Engenharia Urbana) Programa de Pós Graduação em Engenharia Urbana - PPGEU, Universidade Federal de São Carlos, São Carlos, 2012.

BAPTISTA, M.; BARRAUD, S.; NASCIMENTO, N. Técnicas Compensatórias em Drenagem Urbana. 2a edição. Porto Alegre: ABRH, 2011, 318 p.

G-Hidro - Sistemas Hídricos Urbanos. Grupo de Pesquisa. Disponível em: http://dgp.cnpq.br/dgp/espelhogrupo/8736056081026570 Acesso em: maio 2016.

GUTIERREZ, L. A. R. Avaliação da qualidade da água da chuva de um sistema Filtro-Vala-Trincheira de infiltração no tratamento do escoamento superficial direto predial em escala real em São Carlos - SP. 2011. 198 p. Dissertação. (Mestrado em Engenharia Urbana). Programa de Pós Graduação em Engenharia Urbana - PPGEU, Universidade Federal de São Carlos, São Carlos, 2012.

HOLZ, J.; TASSI, R. Usando estruturas não convencionais em grandes áreas: o caso do loteamento Monte Bello. In: XVII SIMPÓSIO BRASILEIRO DE RECURSOS HÍDRICOS, 17, 2007, São Paulo. Anais do XVII Simpósio Brasileiro de Recursos Hídricos, São Paulo, 2007, 19 p. (HOLZ e TASSI, 2007).

IBGE. Instituto Brasileiro de Geografia e Estatística. Censo 2010. Disponível em: < http://censo2010.ibge.gov.br/>. Acesso em: 4 de Fevereiro de 2012.

LUCAS, A. H. Monitoramento e Modelagem de um sistema Filtro - Vala - Trincheira de infiltração em escala real. 2011. Dissertação. (Mestrado em Engenharia Urbana). Programa de Pós Graduação em Engenharia Urbana - PPGEU, Universidade Federal de São Carlos, São Carlos, 2011.

MOURA, T. A. M. Estudo experimental de superfícies permeáveis para o controle de escoamento superficial em ambientes urbanos. 2005. Dissertação. (Mestrado em Tecnologia Ambiental e Recursos Hídricos)Faculdade de Tecnologia - Universidade de Brasília, Brasília, DF.

SANTOS, V. D. Drenagem urbana em áreas especiais: o caso da bacia fechada do bairro Oitizeiro, João Pessoa. 2006.75 p. Dissertação. (Mestrado em Engenharia Urbana). Centro de Tecnologia - Universidade Federal da Paraíba, João Pessoa, 2006. 
TAVANT, D. R. Desenvolvimento urbano de Baixo Impacto aplicado ao processo de planejamento urbano. 2009, 149 p. (Mestrado em Engenharia Urbana) - Programa de Pós Graduação em Engenharia Urbana - PPGEU, Universidade Federal de São Carlos, São Carlos, 2009.

TECEDOR, N.; BAPTISTA, L. F. S.; FELIPE, M. C.; BARBASSA, A. P. Aspectos sustentáveis das técnicas compensatórias em drenagem urbana aplicadas no campus da UFSCar. In: 5o Simpósio em Tecnologia doMeio Ambiente e Recursos Hídricos. FATEC - Jahu - SP. Anais do 5o Simpósio em Tecnologia do Meio Ambiente e Recursos Hídricos. 2013. p. 18-31.SILVA (2015).

TUCCI, C. E. M. Inundações Urbanas. In: Carlos E. M. Tucci; Rubem La Laina Porto; Mário T. de Barros. (Org.). Drenagem Urbana. 1ed. Porto Alegre: Editora da Universidade (UFRGS) - ABRH Assoicação Brasileira de Recursos Hídricos, v. 1,1995. p. 15-36.

VIESSMAN W, KNAPP JW, LEWIS GL. Introduction to Hydrology. Harper and Row Publishers, New York. (1989). 